\title{
EMPREENDEDORISMO E ESTRATÉGIA SOB A ÓTICA DA LÓGICA EFFECTUATION
}

\section{ENTREPRENEURSHIP AND STRATEGY THE PERSPECTIVE OF LOGIC EFFECTUATION}

\section{EMPRENDIMIENTO Y LA ESTRATEGIA DE LA PERSPECTIVA DE EFECTIVIZACIÓN LÓGICA}

\section{Emanuelly Alves Pelogio}

Mestre em Administração pela Universidade Federal do Rio Grande do Norte - UFRN

Professora do Instituto Machadense de Ensino Superior - IMES

E-mail: manu-pelagio@bol.com.br (Brasil)

\section{Luiz Célio Souza Rocha}

Mestre em Administração pela Universidade Federal do Rio Grande do Norte - UFRN Professor do Instituto Federal de Educação, Ciência e Tecnologia do Sul de Minas Gerais E-mail: luiz.rocha@mch.ifsuldeminas.edu.br (Brasil)

\section{Hilka Vier Machado}

Doutora em Engenharia de Produção pela Universidade Federal de Santa Catarina - UFSC Professora da Universidade Estadual de Maringá - UEM

E-mail: hilkavier@yahoo.com (Brasil)

\section{Miguel Eduardo Moreno Añez}

Pós-Doutor em Administração Internacional pela École des Hautes Études Commerciales de Montréal,Canadá

Professor do Programa de Pós-Graduação em Administração da Universidade Federal do Rio Grande do Norte - PPGA/UFRN

E-mail: anez1957@yahoo.com.br (Brasil) 


\title{
RESUMO
}

Os empreendedores são parte de um ambiente dinâmico e incerto que envolve múltiplas decisões, que são interdependentes e simultâneas. Porém, a ação do empreendedor tem sido bastante questionada. Um dos principais questionamentos que se faz ante esta estratégia do empreendedor é que ela não é planejada de modo coerente ou prescrita de maneira determinista, da forma que muitas pesquisas em empreendedorismo e estratégia parecem enfatizar. Desta forma, o presente artigo tem como objetivo realizar uma construção teórica destinada a expor e discutir o tema empreendedorismo e estratégia sob a ótica da lógica Effectuation, que é um modelo de tomada de decisão alternativo ao modelo de tomada de decisão clássico. Para tanto, realizou-se um estudo bibliográfico, exploratório e com abordagem de análise qualitativa. Conclui-se que há a necessidade de considerar outras abordagens que compreendam a ação do empreendedor sob uma visão não determinística e não-linear.

Palavras-chave: Empreendedorismo; Empreendedor; Estratégia, Effectuation; Modelo de Tomada de Decisão.

\section{ENTREPRENEURSHIP AND STRATEGY THE PERSPECTIVE OF LOGIC} EFFECTUATION

\begin{abstract}
Entrepreneurs are part of a dynamic and uncertain environment involving multiple decisions, which are interdependent and simultaneous. However, the action of the entrepreneur has been widely questioned. One of the main questions made about this entrepreneur's strategy is that it isn't consistently planned or prescribed in a deterministic way, the way that a lot of research in entrepreneurship and strategy seem to emphasize. Thus, this paper aims to conduct a theoretical construct designed to expose and discuss the topic entrepreneurship and strategy from the perspective of Effectuation logic, which is a alternative decision making model to the classic decision making model. Therefore, we carried out a bibliographic, exploratory and with qualitative analysis approach study. We conclude that there is a need to consider other approaches to understand the action of the entrepreneur in a non deterministic and nonlinear sight.
\end{abstract}

Keywords: Entrepreneurship; Entrepreneur; Strategy; Effectuation; Decision Making Model. 


\section{EMPRENDIMIENTO Y LA ESTRATEGIA DE LA PERSPECTIVA DE EFECTIVIZACIÓN LÓGICA}

\section{RESUMEN}

Los empresarios son parte de un entorno dinámico e incierto que implica múltiples decisiones que son interdependientes y simultáneos. Sin embargo, la acción del empresario ha sido ampliamente cuestionada. Una de las principales preguntas que se hacen antes de que este empresario de la estrategia es que no se ha previsto o prescrito de forma determinista, la forma en que una gran cantidad de investigación en el espíritu empresarial y la estrategia parece enfatizar constantemente. Por lo tanto, este artículo tiene como objetivo hacer una construcción teórica diseñada para exponer y debatir la iniciativa empresarial y la estrategia tema desde el punto de vista de la lógica efectivización, que es un modelo de toma de decisiones para un modelo alternativo de toma de decisión clásica. Por lo tanto, se realizó un estudio bibliográfico, exploratorio y enfoque de análisis cualitativo. Llegamos a la conclusión de que existe una necesidad de considerar otros enfoques para comprender la acción del empresario de una manera no determinista y lineal.

Palabras-clave: Emprendimiento; Emprendedor; Estrategia de Consecución; Effectuation; Modelo de Toma de Decisiones. 


\section{INTRODUÇÃO}

As transformações contínuas do mundo e da sociedade acarretam consequências para os negócios. Neste cenário, as empresas enfrentam o desafio de se moldarem a estas transformações, que propiciam oportunidades e, ao mesmo tempo, testam suas capacidades, a fim de garantirem seu bom êxito no curto e longo prazo. No entanto, é impossível estabelecer critérios únicos de planejamento e estratégias que se apliquem à realidade das empresas contemporâneas. De uma forma geral, não há estratégia modelo a ser aplicada nas empresas, mas estratégia a ser aplicada em uma determinada empresa, em um mercado específico e modificada quando as condições do ambiente interno e/ou externo assim anunciarem (Oliveira Filho; Grossi, 2010).

Neste sentido, até pouco tempo, tinha-se a ideia que procedimentos e atitudes padronizadas bastavam para o sucesso nos negócios. Porém, tal ideia encontra-se em processo de transformação, uma vez que as próprias condições nas quais as empresas são criadas atualmente são muito diferentes do que no passado. Desta forma, o empreendedor necessita dirigir e gerenciar os negócios de forma criativa e inovadora, valendo-se das inovações tecnológicas existentes e que tem provocado grandes transformações na sociedade. Afinal, de acordo com Tasic (2007), os ambientes em que os empreendedores vivem e os mercados nos quais atuam são, essencialmente, incertos, não havendo, portanto, possibilidade de se conhecer, a priori, a distribuição futura de eventos.

Sob incerteza, o processo de escolha e decisão dos agentes humanos é ambíguo, assim como os objetivos que eles estabelecem. Assim, o ambiente no qual os empreendedores atuam é dinâmico e incerto, cheio de múltiplas decisões, que são interdependentes e simultâneas. Portanto, a ideia de racionalidade limitada e de ambiguidade de objetivos parece caracterizar o processo de empreender (Sarasvathy, 2001a). É a partir da ação do empreendedor que as aspirações genéricas começam a se cristalizar em novos negócios. Porém, esta intervenção tem sido bastante questionada. Um dos principais questionamentos que se faz ante esta estratégia do empreendedor é que ela não é planejada de modo coerente ou prescrita de maneira determinista, conforme muitas pesquisas em empreendedorismo e estratégia parecem enfatizar. Portanto, há a necessidade de considerar outras abordagens que compreendam a ação do empreendedor sob uma visão não- determinística e nãolinear.

Neste contexto, o objetivo deste ensaio é realizar uma construção teórica destinada a expor e discutir o tema empreendedorismo e estratégia sob a ótica da lógica Effectuation, que é um modelo de tomada de decisão alternativo ao modelo de tomada de decisão clássico. Assim, o intuito deste ensaio é fortalecer e contribuir para melhor compreensão do assunto, dada sua importância no contexto atual das organizações. 
Emanuelly Alves Pelogio, Luiz Célio Souza Rocha, Hilka Vier Machado \& Miguel Eduardo Moreno Añez

\section{EMPREENDEDORISMO, EMPREENDEDOR E ESTRATÉGIA EFFECTUAL}

O empreendedorismo é um fenômeno complexo que abrange uma variedade de contextos (JULIEN, 2010). Os diversos conceitos utilizados na literatura sobre o tema refletem essa complexidade.

Fazer da ideia, oportunidade, correr riscos e buscar a realização pessoal, são alguns componentes que movem o ato de empreender (PELOGIO et al., 2011). O empreendedorismo é um tema que emergiu nos meios acadêmicos com maior intensidade nos últimos vinte anos. Mas, sua importância para o desenvolvimento econômico, já foi tema de estudos de autores como Schumpeter (1988), Gartner (1985), Filion (1999), Dornelas (2001) e Hisrich e Peters (2002), entre outros pesquisadores em todo o mundo.

Dentro da temática do empreendedorismo, vários estudos também abordam questões relacionadas às reais causas de sucesso ou fracasso de novos empreendimentos, às características de empresas e de empreendedores de sucesso, ou ainda, ao modo como deve ser o plano de negócios ou a análise competitiva ideal de um novo empreendimento de forma que se reduzam chances de fracasso (DORNELAS, 2001, GEM, 2010, TASIC, 2007). Enfim, estas parecem ser questões centrais que vêm sendo apresentadas neste campo de estudo. Mas, as respostas a estes questionamentos são, no entanto, pouco conclusivas. Afinal, também parece existir consenso entre acadêmicos e praticantes do empreendedorismo de que é quase impossível chegar a um padrão definitivo a respeito da forma ideal ou padrão de se estabelecer um novo empreendimento, seja no Brasil, seja em outro país, mais ou menos desenvolvido (TASIC, 2007).

Diversos autores buscaram conceituar o que seria o processo empreendedor. Hisrich e Peters (2002) definem o processo empreendedor em quatro partes: (1) Identificação e avaliação de oportunidades; (2) Desenvolvimento do plano de negócios; (3) Determinação dos recursos necessários; e (4) Gestão da empresa. Desta forma, percebe-se que o processo empreendedor é usualmente desenhado como deliberado, linear, e, em grande parte, racional, no sentido em que há uma busca intencional por oportunidades, sua avaliação, mensuração e, por fim, a ação do empreendedor no intuito de criar a empresa (HISRICH; PETERS, 2002).

Ao se avaliar as origens do conceito, o termo "empreendedor" já era usado desde a idade média para descrever tanto um ator quanto uma pessoa que gerenciava grandes projetos de produção (construção de castelos, fortes etc.). Já no século XVII é feita a primeira associação do empreendedorismo à noção de risco, na medida em que o empreendedor era aquele que assumia certo grau de risco ao financiar contratos ou realizar serviços com o governo. Mas é no século 
XVIII e XIX, com os conceitos de Cantillon e Say, que o termo empreendedor passa a assumir um caráter mais próximo de empresário, diferenciando-o do capitalista e agregando-lhe a função primária de transformação de matérias-primas em produtos e serviços com valor econômico (FILION, 1999, HISRICH; PETERS, 2002).

O empreendedorismo, conforme Carland, Hoy e Boulton (1984), está ligado ao conceito de competência, pois na formação do empreendedor deve-se procurar a aquisição de conhecimentos, habilidades, experiências, capacidade criativa e inovadora. Para Schumpeter (1988), a essência do empreendedorismo está na percepção e na exploração de novas oportunidades, no âmbito dos negócios, utilizando recursos disponíveis de maneira inovadora, onde empreendedor e inovação interagem totalmente.

Na visão de Drucker (1986), empreendedor é aquele que inicia um negócio e tem características específicas a fim de desenvolver, na atividade, um diferencial que o destaque no mercado e faça com que cresça no segmento da atividade, não bastando, porém, ser dono e assumir riscos para ser considerado empreendedor. Já de acordo com Filion (1999), o significado da palavra empreendedor pode variar de acordo com o país e a época. Para o autor, o empreendedor é uma pessoa que imagina, desenvolve e realiza visões.

No entanto, apesar da nítida confusão acerca do termo "empreendedor" e “empreendedorismo" (FILION, 1999), o empreendedorismo consiste no fenômeno da geração de negócios em si, relacionado tanto com a criação de uma empresa, quanto com a expansão de alguma já existente, a exemplo do desenvolvimento de uma unidade de negócio no contexto da grande corporação (PAIVA; CORDEIRO, 2006). Na mesma linha, empreendedorismo poderia ser entendido como qualquer tentativa de criação de um novo negócio ou novo empreendimento ou a expansão de um empreendimento existente por um indivíduo ou grupos de indivíduos e empresas já estabelecidas (GEM, 2009).

Embora não exista um consenso sobre o conceito de empreendedor e empreendedorismo, a noção de que os empreendedores desempenham uma função social de identificar oportunidades, convertendo-as em valores econômicos é observada (JULIEN, 2010). Neste sentido, existe uma ampla gama de definições que associam a prática de empreender como o ato de criação de uma organização econômica inovadora (ou redes de organizações) para o propósito de obter lucratividade ou crescimento sob condições de risco e incerteza (DOLLINGER, 1995, GARTNER, 1985, SCHUMPETER, 1988).

Quando se aborda a figura do empreendedor é importante pensar nele como um dos papéis assumidos pelo indivíduo na condução dos negócios, relacioná-lo com o meio no qual está inserido 
e por fim considerar que a forma de trabalho do empreendedor é o reflexo de si próprio e do meio em que vive (JULIEN, 2010).

\section{ESTRATÉGIA: DEFINIÇÕES E ABORDAGENS}

Sobre o conceito de estratégia, Ansoff e McDonnell (1993) afirmam que estratégia é um conjunto de regras de tomada de decisão que orienta o comportamento de uma organização. No entanto, afirmam também que esse conceito de estratégia é fugaz e um tanto abstrato e sua aplicabilidade deve estar alinhada com o pragmatismo orientado para resultados intrínsecos à administração. Ao estrategista cabe, portanto, o dever de prever o futuro, reduzindo o amanhã incalculável a um padrão previsível e, portanto, controlável (PEIXOTO; NERY, 2010). Dessa forma, a empresa busca formalizar os critérios que a guiará até que se atinja um objetivo determinado, que na perspectiva desses autores são as atitudes que a organização terá diante do contexto em que participa que a levará ao sucesso.

Em consonância com as teorias clássicas, "fazer estratégia” é um processo de planejamento deliberado (formal), iniciado pela cúpula (hierárquico), com base em análise elaborada racionalmente e focada no desenvolvimento de uma estratégia organizacional coesa (PEIXOTO; NERY, 2010). Visões como esta, que abordam as estratégias como regras, sobretudo como sendo padrões rígidos, que geralmente são seguidos para guiar a organização a um objetivo previamente traçado pelos executivos do alto escalão organizacional, subscrevem a noção racional da estratégia corporativa que domina as escolas de administração e a administração ocidental contemporânea, pois acreditam que tudo é potencialmente identificável nos ambientes dos negócios (PEIXOTO; NERY, 2010).

Whittington (2002), em seu trabalho sobre o que é a estratégia, constrói uma síntese bem explicativa das correntes do pensamento estratégico e tratou quatro diferentes abordagens acerca da administração estratégica: a clássica; a evolucionária; a processual e a sistêmica. O Quadro 01 apresenta resumidamente as principais características de cada uma delas: 
Empreendedorismo e Estratégia sob a Ótica da Lógica Effectuation

\begin{tabular}{|ll|}
\hline Abordagens & \multicolumn{1}{c|}{ Principais Características } \\
\hline Clássica & Vê a estratégia como processo racional de planejamento de longo prazo. \\
Evolucionista & $\begin{array}{l}\text { Acredita que o ambiente é muito volátil e imprevisível para ser planejado. } \\
\text { Portanto, a melhor estratégia é a organização se concentrar na } \\
\text { maximização das chances de sobrevivência que se apresentam no dia-a- } \\
\text { dia. }\end{array}$ \\
Srocessualista & $\begin{array}{l}\text { Questiona o planejamento formal, acreditando que a estratégia é um } \\
\text { processo emergente de aprendizado e adaptação. }\end{array}$ \\
& $\begin{array}{l}\text { Assume uma posição relativista, pois defende que formas e metas do } \\
\text { desenvolvimento de estratégias dependem particularmente do contexto } \\
\text { social. Portanto, a estratégia deve ser empreendida como sensibilidade } \\
\text { sociológica. }\end{array}$ \\
\hline
\end{tabular}

Quadro 1 - Abordagens Estratégicas

Fonte: Peixoto e Nery (2010).

Assim, Whittington (2002) ao elaborar essas quatro abordagens que oferecem recomendações diferentes sobre o processo estratégico, ele, na realidade, levanta um debate que permite questionar a validade da estratégia como algo rígido, formal, em que o seu processo de gênese é realizado mediante reuniões da alta gerência, em que todos estão munidos de relatórios cheios de dados estatísticos que traçam racionalmente o futuro da organização (PEIXOTO; NERY, 2010).

Já de acordo com Wiltbank et al. (2006), estudos na corrente de administração estratégica resumem duas prescrições fundamentais para o modo como as empresas podem tomar decisões estratégicas: elas deveriam tentar mais duramente melhor predizer (Estratégias Racionais defendidas pela Escola de Planejamento) ou mover-se mais rapidamente para melhor adaptar-se (Estratégias Adaptativas defendidas pela Escola de Aprendizagem). Entretanto, uma característica fundamental de ambas as abordagens, de planejamento ou adaptativa, é a ênfase em posicionar a organização dentro de um ambiente dado. As duas abordagens diferem principalmente em como elas competem com o que é dado incertamente (WILTBANK et al., 2006).

A Escola de Planejamento é talvez a mais velha dentro da administração estratégica e enfatiza a importância da análise sistemática, do planejamento integrativo e da avaliação racional de informação, estas são algumas das características do processo de planejamento racional. A visão do planejamento racional prediz que como as incertezas aumentam, as organizações que trabalham mais diligentemente para analisar e prever com mais precisão a situação de mudança na qual elas operam vão ultrapassar aquelas organizações que não o fazem (WILTBANK et al., 2006). 
A Escola de Aprendizagem, ou Adaptativa, em oposição a Escola de Planejamento, sugere que as organizações aprendem o que fazer minimizando o uso de racionalidade preditiva, e experimentam mover-se depressa para capturar novas oportunidades (WILTBANK et al., 2006). O princípio estratégico básico das abordagens adaptativas é o incrementalismo: a empresa aprende do feedback do ambiente e a estratégia subsequente reflete esta aprendizagem. Como o ciclo de ação e avaliação é curto, abordagens adaptativas enfatizam o reconhecimento de onde o ambiente está ao invés de prever onde ele estará, se colocando em rápida adaptação ao invés de intenções estratégicas (WILTBANK et al., 2006).

Abordagens determinísticas em administração estratégica se moldam em uma concepção básica: previsão é útil na tomada de decisão estratégica porque as consequências do que pode ser predito pode ser controlado. Esta abordagem espelha a ciência, onde a previsão é usada para testar teorias sobre conexões causais dentro do ambiente natural e essas teorias são então usadas para manipular a natureza para nossos fins, ou para seguramente se posicionar contra as incontroláveis forças da natureza (WILTBANK et al., 2006).

Wiltbank et al. (2006), em seu estudo, sugerem quatro abordagens-chave para a tomada de decisão estratégica de empreendedores, como mostram as Figuras 01 e 02:

- Eles podem assumir que o ambiente está além de seu controle e previsão, investindo em técnicas preditivas que lhes permitem posicionar favoravelmente para o futuro (Planejamento de Estratégias).

- Eles podem assumir que o ambiente é imprevisível, então encurtam seus horizontes de planejamento e investem em estratégias flexíveis que efetivamente respondem a mudanças no ambiente (Estratégias Adaptativas).

- Eles podem assumir que o ambiente é previsível, mas maleável e impõem sua visão do futuro, moldando o ambiente para alcançar seus resultados favoráveis (Estratégias Visionárias).

- Eles podem assumir que os fatores ambientais futuros são largamente não existentes, e buscam criá-los através de cooperação e criação de metas com parceiros para imaginar possíveis futuros que se estendem do meio atual (Estratégias Transformativas baseadas na lógica Effectuation). 
Figura 1- Abordagens da previsão e do controle

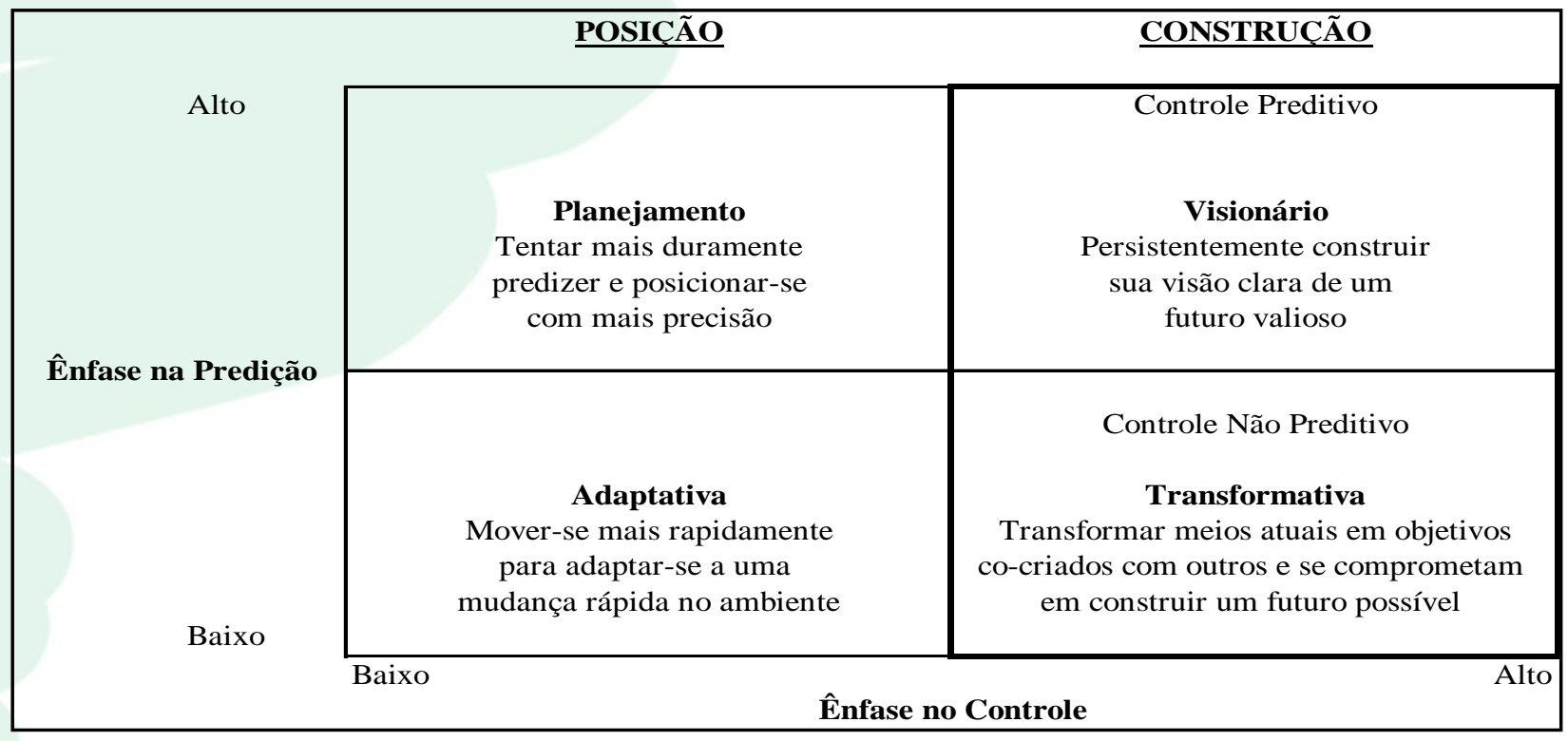

Fonte: Traduzido de Wiltbank et al., (2006).

\begin{tabular}{|c|c|c|}
\hline & POSICÃ̃O & CONSTRUÇ̃̃O \\
\hline 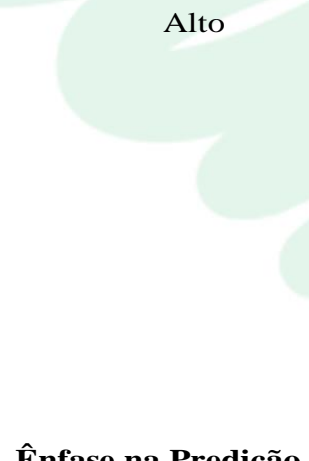 & \begin{tabular}{|c|} 
Planejamento \\
Planejamento e Posicionamento \\
(Ansoff, 1979) \\
Análise Competitiva \\
(Porter, 1980) \\
Opções Reais \\
(McGrath, 1999) \\
Planejamento de Cenários \\
(Schoemaker, 2002)
\end{tabular} & $\begin{array}{c}\text { Visionário } \\
\text { Imaginação Corporativa } \\
\text { (Hamel e Prahalad, 1991) } \\
\text { Visão } \\
\text { (Tellis e Golder, 2002) } \\
\text { Modelamneto de Estratégias } \\
\text { (Courtney et al., 1997) } \\
\text { Projeção estratégica } \\
\text { (Rindova e Fombrun, 1999) }\end{array}$ \\
\hline Baixo & \begin{tabular}{l}
$\begin{array}{l}\text { Rápida Tomada de Decisão } \\
\text { (Eisenhardt, 1989) }\end{array}$ \\
Capacidades Dinâmicas \\
(Teece, Pisano, e Shuen, 1997) \\
Incrementalismo \\
(Quinn, 1980) \\
$\begin{array}{l}\text { Estratégias Emergentes } \\
\text { (Mintzberg, 1994) }\end{array}$ \\
\multicolumn{1}{c}{ Adaptativa }
\end{tabular} & $\begin{array}{l}\text { Criação de Curva de valor } \\
\text { (Kim e Maubourgne, 1997) } \\
\text { Apoio no Futuro } \\
\text { (Hayes, 1985) } \\
\\
\text { Effectuation } \\
\text { (Sarasvathy, 2001a) } \\
\text { Transformativa }\end{array}$ \\
\hline
\end{tabular}

Figura 2 - Literatura representativa de abordagens específicas para controle de situação 
Emanuelly Alves Pelogio, Luiz Célio Souza Rocha, Hilka Vier Machado \& Miguel Eduardo Moreno Añez

Fonte: Traduzido de Wiltbank et al., (2006).

Assim, como esboçado no lado direito das Figuras 01 e 02, as estratégias de construção diferem em sua ênfase na previsão, assim, estão separadas em Estratégias Visionárias e Transformativas. A Estratégia Visionária e a Estratégia como Transformação diferem dependendo da existência e claridade de objetivos, a disponibilidade e qualidade de meios, e as habilidades do estrategista (WILTBANK et al., 2006).

Abordagens Visionárias têm conexões fortes com abordagens preditivas para estratégia, e encarna noções de percepção e empreendedores persistentes que parecem impor sua ideia ao mundo (WILTBANK et al., 2006). Já as Abordagens Transformativas focam na co-criação de objetivos com outros em um processo mutuamente persuasivo onde a ação precede frequentemente objetivos claros e resultados preditos (WILTBANK et al., 2006). Atores que usam este tipo de estratégia transformam os meios existentes em novos futuros. Sarasvathy (2001a, 2001b) baseia-se em Simon e March para mostrar como os empreendedores usam uma lógica effectual, que é uma Abordagem Transformativa, sem o uso da previsão ou visão na criação de novos mercados e novos ambientes.

\section{A LÓGICA EFFECTUATION E SEUS PRINCÍPIOS}

Effectuation, definida por Sarasvathy (2001a, 2001b), é uma lógica que consiste em tomar decisões a partir de escolhas entre os efeitos que podem ser produzidos de um dado conjunto de meios, eliminando, consequentemente, a premissa de objetivos pré-existentes.

Por "lógica", entende-se um conjunto de ideias interiormente consistentes que formam uma base clara para ação. No contexto de uma empresa, esta base consiste (amplamente) da negociação de objetivos, ambientes em transformação e estratégias baseadas no aproveitamento e transformação das contingências do ambiente. Em outras palavras, Effectuation não assume objetivos predeterminados e claramente específicos. Os objetivos emergem como parte de negociações com parceiros. Estas negociações com parceiros não só resultam em novos objetivos de oportunidades que a empresa busca realizar, mas também explicitamente reforma e transforma o ambiente no qual a organização opera. Neste sentido, empreendedores que usam a lógica effectual agem não só em ambientes de mercado, mas também neles e, em alguns casos, acabam criando novos mercados não preditos até mesmo pelos muitos parceiros envolvidos no processo de negociação. Não tomar o ambiente como determinado ou previsível implica que tipos de estratégias adaptáveis reativas sejam inadequados e até mesmo impróprios no processo effectual. 
O modelo effectual é resumido por Sarasvathy (2001a, 2001b) em quatro princípios:

- Perdas aceitáveis, ao invés de retornos esperados: modelos baseados em causalidade baseiam-se na maximização do retorno potencial de uma decisão, selecionando estratégias ótimas (que otimizem a relação meios/retorno). No processo effectual, o tomador de decisão (o empreendedor, no caso) determina previamente um nível de perda aceitável e experimenta tantas estratégias quanto possíveis, dadas a limitada dotação de recursos disponíveis. O effectuator prefere opções (estratégias) que criem mais opções no futuro do que aquelas que maximizam o retorno esperado no presente.

- Alianças estratégicas, ao invés de análises competitivas: os modelos de causalidade, como o modelo de estratégia de Porter (1980), enfatizam análises competitivas detalhadas (em várias dimensões) sobre a competição em determinado mercado. O modelo effectual, por outro lado, enfatiza alianças estratégicas e pré-comprometimentos com stakeholders, como uma forma de reduzir e/ou eliminar incertezas e construir barreiras que reduzam a competição num determinado mercado (diminuindo a concorrência).

- Exploração de contingências, ao invés da utilização de conhecimento pré-existente: quando o conhecimento pré-existente, tal como experiência pessoal ou o domínio de uma nova tecnologia, representa a principal fonte de vantagem competitiva, modelos de causalidade podem ser preferíveis. O modelo effectual, entretanto, pode ser um processo mais apropriado para explorar contingências que surgem inesperadamente ao longo do tempo.

- Controlar um futuro imprevisível, ao invés de prever um futuro incerto: os processos decisórios baseados na causalidade se baseiam nos aspectos previsíveis de um futuro incerto. A lógica para usar os processos baseados na causalidade é: na medida em que podemos prever o futuro, podemos controlá-lo. O modelo effectual: na medida em que nós podemos controlar o futuro, não necessitamos prevê-lo. 
Emanuelly Alves Pelogio, Luiz Célio Souza Rocha, Hilka Vier Machado \& Miguel Eduardo Moreno Añez

\subsection{UMA ABORDAGEM ESTRATÉGICA TRANSFORMATIVA: O PROCESSO EFFECTUAL}

O modelo estratégico dinâmico e interativo Effectuation (Figura 04) delineia um processo específico de como as organizações podem criar o que fazer sob incerteza. O processo é orientado à ação, intersubjetivo e, sem usar modelos preditivos, transforma um meio organizacional do empreendedor em novos conjuntos de meios/fins construídos.

O processo effectual, como demonstram Wiltbank et al. (2006), parte de três categorias básicas de meios (do empreendedor): Identidade; Conhecimento; e Redes Sociais.

Figura 3 - Uma abordagem transformativa: o processo effectual - dinâmico e interativo.

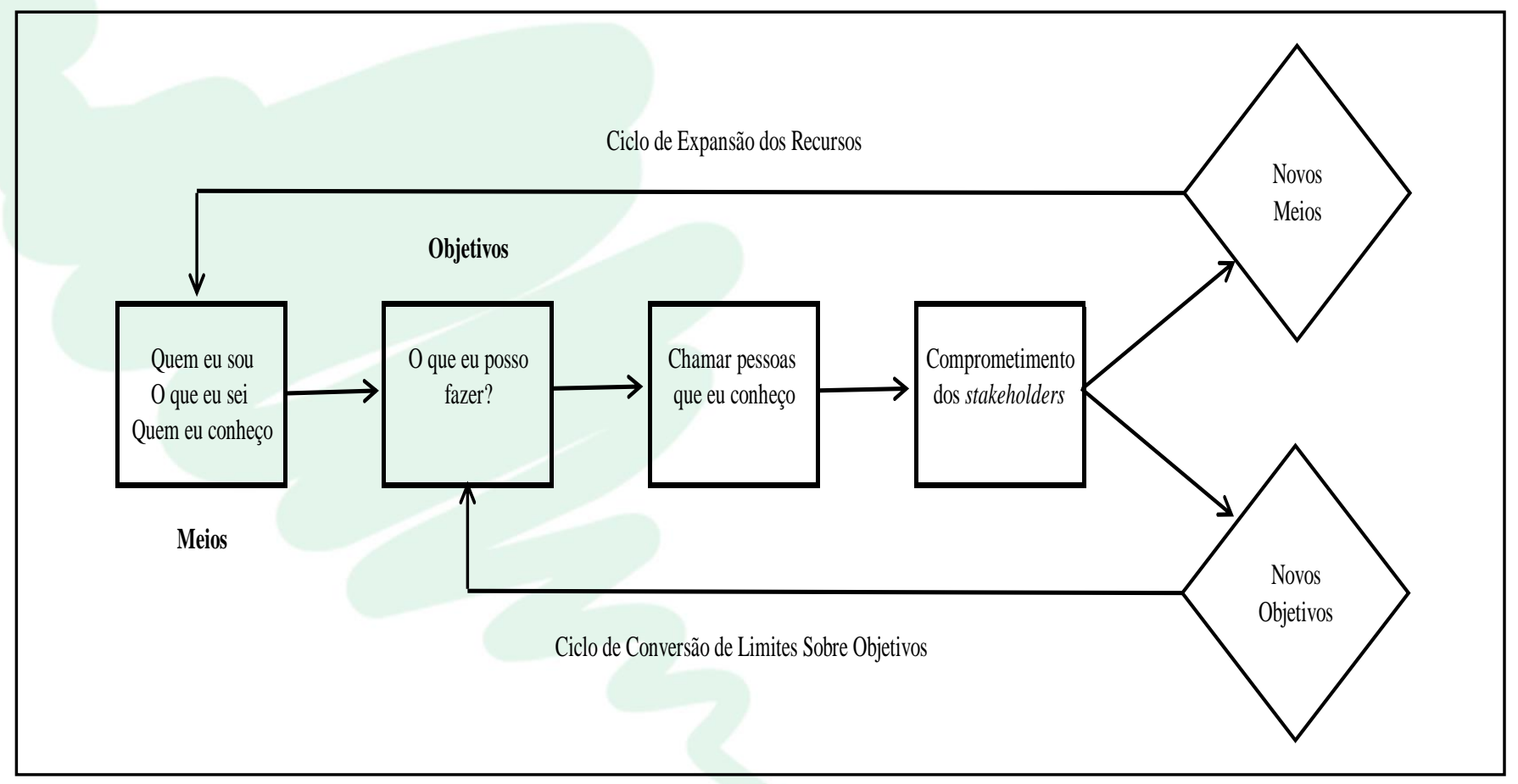

Fonte: Wiltbank et al., (2006).

Os empreendedores começam por quem eles são, o que eles conhecem e quem eles conhecem de forma a imaginar coisas que eles possam vir a realizar. Isto reflete uma ênfase em eventos futuros que eles podem controlar ao invés de prever (WILTBANK et al., 2006). Em seguida, segundo os autores, os empreendedores começam a divulgar seu projeto para outras pessoas de modo a obter inputs sobre como proceder com algumas das coisas que eles poderiam (possivelmente) fazer. As pessoas com quem eles conversam poderiam ser potenciais stakeholders, 
amigos e familiares ou pessoas aleatórias que eles conhecem ao longo do tempo. À medida que os empreendedores encontram pessoas que queiram participar nos esforços de construir algo ("algo" pode ser vago ou concreto, mas está sempre aberto a mudanças), eles prosseguem no sentido de obter comprometimentos reais destes stakeholders potenciais (WILTBANK et al., 2006).

O que tem importância, segundo Tasic (2007), é a vontade dos stakeholders em se comprometer no processo de construção e não o alinhamento com alguma visão ou oportunidade pré-concebida. Cada pessoa que, de fato, aposta algo para entrar no empreendimento contribui no refinamento da visão e da oportunidade, ao passo que ajuda a viabilizar e executar estratégias únicas para alcançá-las (TASIC, 2007).

Qualquer parte do compromisso do stakeholder se transforma, então, em um "retalho" de uma "colcha" cada vez maior, cujo padrão passa a fazer sentido apenas por meio de contínuas negociações e re-negociações de sua proposta para que novos stakeholders embarquem no empreendimento (TASIC, 2007). Em outras palavras, stakeholders comprometem recursos em troca de uma oportunidade de remodelar os objetivos do projeto, de influenciar qual futuro em última instância será criado.

Finalmente, este processo de negociação e persuasão define dois ciclos na formação paralela de uma nova empresa e um novo mercado: (a) um ciclo expansivo que aumenta os meios disponíveis e (b) um conjunto convergente de restrições sobre os objetivos da crescente rede de stakeholders (TASIC, 2007).

Em algum ponto no processo effectual, contudo, o ciclo convergente encerra o processo de aquisição de stakeholders e o espaço para negociações e re-adaptações do formato daquilo que será criado e a dependência mútua terminam. À medida que as estruturas da empresa e do mercado começam a se tornar visíveis, pode ser importante a reavaliação do equilíbrio entre previsão e controle, como abordagem estratégica (TASIC, 2007).

\subsection{EMPREENDEDORISMO E ESTRATÉGIA SOB A ÓTICA DA LÓGICA EFFECTUATION}

Os modelos clássicos de estratégia e decisão consideram um determinado efeito como dado e se concentram na seleção de meios (causas) que possam produzir o efeito desejado. O modelo Effectuation considera um conjunto de meios (causas) como dados e se concentra na seleção (escolha) entre possíveis efeitos que podem ser criados com aquele conjunto de meios. Esta é a essência da noção de processo empreendedor proposta por Sarasvathy (2001a, 2001b): o modelo de tomada de decisão Effectuation, que é a forma de tomar decisões a partir de escolhas dentre os 
efeitos que podem ser produzidos a partir de um dado conjunto de meios, eliminando, consequentemente, a premissa de objetivos pré-existentes. Desta forma, vários estudos empíricos sugerem que os empreendedores usam elementos não preditivos nos processos de construção de novas empresas, ou seja, os empreendedores se comportam estrategicamente sob uma lógica effectual (WILTBANK et al., 2006).

De acordo com a lógica Effectuation, o tomador de decisão (empreendedor) tem papel central no processo de criação das empresas e é parte de um ambiente dinâmico, envolvendo múltiplas decisões, que são interdependentes e simultâneas. Afinal, é a partir da ação estratégica do empreendedor que as aspirações genéricas começam a se cristalizar em novos negócios. Mas, como aponta Sarasvathy (2001a), esta intervenção não é planejada de modo coerente ou prescrita de maneira determinista, da forma que muitas pesquisas em empreendedorismo e estratégia parecem enfatizar. Ao contrário, a autora defende a ideia de um processo não-linear, que é fortemente pautado pelos pressupostos do modelo effectuation, na medida em que o empreendedor opta pelo controle de alguns aspectos de um futuro imprevisível, ao invés de tentar prevê-los. Por esta lógica, segundo a autora, os empreendedores focam em quanto eles suportam perder e experimentam várias estratégias distintas e combinações de recursos quanto possíveis, dados os recursos que já estão sob seu controle. O objetivo, na lógica effectual, é reduzir a incerteza de certas estratégias e combinações de recursos, e não maximizar os retornos financeiros potenciais (SARASVATHY, 2001a, 2001b).

Assim, de acordo com Sarasvathy (2001b), Effectuation é o inverso de causalidade. Neste sentido, a racionalidade effectual não é meramente um desvio da racionalidade clássica causal, é, sim, um modo de racionalidade alternativo, baseado em uma lógica distinta da lógica causal (SARASVATHY, 2001b).

Embora a programação estratégica causal (planos formais) possa ser útil ao empreendedor em ambientes mais estáveis, alocações de recursos mais complexas ou de forma cerimonial, a formação estratégica em empresas empreendedoras se dá essencialmente via um processo de aprendizado, na qual as estratégias emergem a partir de um conjunto de ações realizadas ao longo do tempo (MINTZBERG; WATERS, 1982).

As diferenças-chave entre a estratégia de tomada de decisão preditiva e effectual são resumidas no Quadro 02. 
Empreendedorismo e Estratégia sob a Ótica da Lógica Effectuation

\begin{tabular}{|c|c|c|}
\hline $\begin{array}{l}\text { Categorias de } \\
\text { diferenciação }\end{array}$ & Processos Causais & Processos de Effectuation \\
\hline Dados & Efeito é dado & $\begin{array}{l}\text { Apenas alguns meios e ferramentas } \\
\text { são dados }\end{array}$ \\
\hline \multirow{3}{*}{$\begin{array}{l}\text { Critérios de seleção } \\
\text { para a tomada de } \\
\text { decisão }\end{array}$} & $\begin{array}{l}\text { Ajuda a escolher entre meios para } \\
\text { alcançar o efeito dado }\end{array}$ & $\begin{array}{l}\text { Ajuda a escolher entre possiveis } \\
\text { efeitos que podem ser criados com } \\
\text { meios dados }\end{array}$ \\
\hline & $\begin{array}{l}\text { Critério de seleção baseado em } \\
\text { retornos esperados }\end{array}$ & $\begin{array}{l}\text { Critério de seleção baseado em } \\
\text { perdas toleráveis ou risco aceitável }\end{array}$ \\
\hline & $\begin{array}{l}\text { Efeito-dependente: escolha de } \\
\text { meios é direcionada pelas } \\
\text { características do efeito que o } \\
\text { tomador de decisão quer criar e seu } \\
\text { conhecimento de possíveis meios }\end{array}$ & $\begin{array}{l}\text { Ator-dependente: dados meios } \\
\text { específicos, a escolha do efeito é } \\
\text { direcionada pelas características do } \\
\text { ator e suas habilidades de descobrir } \\
\text { e usar contingências }\end{array}$ \\
\hline $\begin{array}{l}\text { Competências } \\
\text { empregadas }\end{array}$ & $\begin{array}{l}\text { Excelente em explorar } \\
\text { conhecimento }\end{array}$ & $\begin{array}{l}\text { Excelente em explorar } \\
\text { contingências }\end{array}$ \\
\hline \multirow[b]{2}{*}{ Contexto de relevância } & Mais presente em natureza & Mais presente em ações humanas \\
\hline & $\begin{array}{l}\text { Mais útil em ambientes estáticos, } \\
\text { lineares e independentes }\end{array}$ & $\begin{array}{l}\text { Premissa explícita de ambientes } \\
\text { dinâmicos, não-lineares e } \\
\text { ecológicos }\end{array}$ \\
\hline $\begin{array}{l}\text { Natureza do que não se } \\
\text { pode conhecer }\end{array}$ & $\begin{array}{l}\text { Foco nos aspectos previsíveis de } \\
\text { um futuro incerto }\end{array}$ & $\begin{array}{l}\text { Foco nos aspectos controláveis de } \\
\text { um futuro não previsível }\end{array}$ \\
\hline Lógica central & $\begin{array}{l}\text { Na medida em que nós podemos } \\
\text { predizer o futuro, nós podemos } \\
\text { controlá-lo }\end{array}$ & $\begin{array}{l}\text { Na medida em que nós podemos } \\
\text { controlar o futuro, nós não } \\
\text { precisamos predizê-lo }\end{array}$ \\
\hline Resultados & $\begin{array}{l}\text { Participação de mercado em } \\
\text { mercados existentes por meio de } \\
\text { estratégias competitivas }\end{array}$ & $\begin{array}{l}\text { Novos mercados criados por meio } \\
\text { de alianças e outras estratégias } \\
\text { cooperativas }\end{array}$ \\
\hline
\end{tabular}

Quadro 2 - Diferenças básicas entre processos causais e de Effectuation.

Fonte: Traduzido de Sarasvathy (2002).

Percebe-se uma convergência no campo de estudo do empreendedorismo para a ideia de intencionalidade, onde a ação é normalmente descrita a partir da elaboração sistemática de um plano de negócios, aquisição de recursos e execução deliberada do plano (TASIC, 2007). Novas teorias, no entanto, afirmam que são os processos cognitivos e a noção de emergência estratégica (MINTZBERG, 1978, MINTZBERG; WATERS, 1982) que melhor descrevem o modelo sob o qual empreendedores organizam recursos sob incerteza, delimitam objetivos sob ambigüidade e finalmente agem. Esta é a essência da noção de processo empreendedor proposta por Sarasvathy (2001a, 2001b, 2008).

Neste contexto, uma guinada teórica mais radical no estudo do empreendedorismo (CASTANHAR, 2007) foi proposta por Sarasvathy (2001a, 2001b) ao propor um modelo de decisão que denominou de Effectuation como alternativa ao modelo de decisão clássico que se baseia no princípio de causalidade. Segundo Sarasvathy (2001a, 2001b, 2008), os modelos clássicos de decisão consideram um determinado efeito como dado e se concentram na seleção de meios (causas) que possam produzir o efeito desejado. O modelo de decisão Effectuation considera um conjunto de meios (causas) como dados e se concentra na seleção (escolha) entre possíveis efeitos que podem ser criados com aquele conjunto de meios. A essência da noção de processo 
Emanuelly Alves Pelogio, Luiz Célio Souza Rocha, Hilka Vier Machado \& Miguel Eduardo Moreno Añez

empreendedor proposta por Sarasvathy (2001a, 2001b, 2008), o modelo de decisão Effectuation, é a forma de tomar decisões a partir de escolhas dentre os efeitos que podem ser produzidos a partir de um dado conjunto de meios, eliminando, conseqüentemente, a premissa de objetivos pré-existentes.

De acordo com a lógica Effectuation, o tomador de decisão (empreendedor) tem papel central no processo de criação das empresas e é parte de um ambiente dinâmico, envolvendo múltiplas decisões, que são interdependentes e simultâneas. Segundo Sarasvathy (2001a, 2008), decisões desse tipo requerem um modelo de decisão que transcenda o modelo tradicional de causalidade. $\mathrm{O}$ modelo proposto pela autora seria uma alternativa mais adequada para a situação de criação de novas empresas.

O estudo de Pelogio et al. (2011) buscou analisar a criação de empresas por mulheres empreendedoras, buscando verificar se elas utilizaram estratégias alinhadas à estratégia Effectuation ao longo da criação de suas empresas, o que possibilitou uma visão ampliada do assunto.

No momento da criação das empresas, muitas vezes o empreendedor não tem a consciência que está usando uma estratégia causal ou effectual, pois de acordo com a abordagem Effectuation (SARASVATHY, 2001a, 2001b, SARASVATHY et al., 2005, SARASVATHY, 2008) e Pelogio et al. (2011) observa-se uma ambigüidade inicial de objetivos no momento da criação da empresa. A abordagem Effectuation sugere que existam apenas objetivos vagos no início e conexões específicas dos fundadores com os meios/recursos, em relação ao tipo de empresa formada a partir de "quem eu sou”, "o que eu sei” e "quem eu conheço" (SARASVATHY, 2001a, 2001b, 2008). De acordo com o estudo de Pelogio et al. (2011) os empreendedores têm o objetivo geral de ter uma empresa, mas a noção de como esta empresa gerará receitas e em quais mercados eles irão atuar, muitas vezes é vago.

A abordagem Effectuation também sugere que os empreendedores fazem muito poucas pesquisas de mercado e/ou predições a respeito do valor potencial das escolhas alternativas disponíveis e do modelo de negócio (SARASVATHY, 2008). Desta forma, o estudo de Pelogio et al. (2011) assemelha-se com o que sugere a abordagem Effectuation, pois das cinco empreendedoras entrevistadas, apenas uma delas fez um plano de negócios antes de iniciar sua empresa. As empreendedoras estavam focadas no desenvolvimento de um produto ou serviço diferenciado e não no modelo de negócio e na empresa, isso pode ser considerado um ponto negativo na estratégia effectual.

Como afirma a abordagem Effectual, os objetivos são atraentes mais pelo fato de eles serem "factíveis" do que em função de maximizarem os lucros (SARASVATHY, 2008). De acordo com Sarasvathy (2008), na estratégia effectual o empreendedor determina previamente um nível de perda 
aceitável e experimenta tantas estratégias quanto possíveis, dada a limitada dotação de recursos disponível. Quando faz uso da estratégia effectual, o empreendedor prefere opções (estratégias) que criem mais opções no futuro do que aquelas que maximizam o retorno esperado no presente como ocorre com as estratégias causais, neste caso, a estratégia effectual gera várias oportunidades e não apenas uma, por isso, este é outro aspecto positivo da estratégia effectual (PELOGIO et al., 2011).

As ideias surgem largamente por meio de experiências pessoais, ao invés de esforços deliberados de busca (SARASVAYHY, 2008). Corroborando com a abordagem Effectual, apesar de não haver objetivos claros quanto à nova empresa que estavam criando, os empreendedores, na maioria dos casos, trazem um conjunto de experiências que os permitem visualizarem componentes básicos que deveriam estar presentes no novo negócio, este é outro aspecto positivo da estratégia effectual (PELOGIO et al., 2011). Ainda de acordo com Pelogio et al. (2011), do ponto de vista gerencial, os empreendedores contam com suas próprias experiências de gestão que tinham obtido no mercado para abrir seu negócio.

A ideia de alavancagem sobre as redes sociais está presente na estratégia effectual, ela afirma que empreendedores, no início de seus projetos, tenderão a valer-se mais de estratégias cooperativas do que de estratégias competitivas que são mais ligadas a uma estratégia causal (SARASVATHY, 2008). Similar ao que sugere a abordagem Effectuation, o estudo de Pelogio et al. (2011) mostra que todos os mulheres empreendedores valeram-se mais de estratégias cooperativas no início de suas empresas.

Os objetivos iniciais que os empreendedores tinham para suas empresas não eram claros e precisos, como aponta o estudo de Pelogio et al. (2011), todavia, o fato de possuírem objetivos genéricos dotou a empresa de flexibilidade. De acordo com a abordagem Effectuation (SARAVATHY, 2008), os empreendedores souberam aproveitar corretamente as oportunidades e conseguiram transformar dificuldades e surpresas em bons resultados (PELOGIO et al., 2011).

Desta forma, os resultados do estudo de Pelogio et al. (2011) mostraram que as mulheres empreendedoras estudadas utilizaram, em grande parte, processos decisórios alinhados à estratégia Effectuation ao longo da criação de suas empresas. 
Emanuelly Alves Pelogio, Luiz Célio Souza Rocha, Hilka Vier Machado \& Miguel Eduardo Moreno Añez

\section{CONSIDERAÇÕES FINAIS}

$\mathrm{Na}$ atualidade, a obtenção de competitividade estratégica, fundamental para o sucesso das organizações, requer o desenvolvimento e a utilização de uma mentalidade administrativa diferente capaz de mudar rapidamente em acordo com a percepção da necessidade de alteração (OLIVEIRA FILHO; GROSSI, 2010). Assim, Whittington (2002) defende que as ações estratégicas devem se concentrar mais próximas às práticas (como algo que as pessoas fazem) e que a consecução de estratégia exclusivamente à moda clássica deve ser repensada. Dessa maneira, estrategistas eficazes não são pessoas que se abstraem dos detalhes do dia-a-dia, mas que conseguem extrair do cotidiano as mensagens estratégicas (PEIXOTO; NERY, 2010). Neste sentido, o presente artigo teve como objetivo realizar uma construção teórica destinada a expor e discutir o tema empreendedorismo e estratégia sob a ótica da lógica Effectuation, que é um modelo de tomada de decisão alternativo ao modelo clássico.

Apesar de já existirem várias contribuições no meio acadêmico no sentido de contestar o processo formal de formulação de estratégias, apontando o excesso que se faz do uso da racionalidade (causal e limitada) neste processo, várias organizações ainda adotam a perspectiva clássica (PEIXOTO; NERY, 2010). Para algumas dessas organizações o processo formal de formulação de estratégias se mostrou ineficaz diante do contexto altamente mutável e globalizado, como é o caso de várias organizações que mesmo tendo estratégias ditas "ótimas" demonstraram desempenho ineficiente diante de crises econômicas (PEIXOTO; NERY, 2010).

Diante do exposto, tem-se evidência crescente (WILTBANK et al., 2006) que os empreendedores cada vez mais se comportam estrategicamente sob uma lógica effectual, quer dizer, eles agem e tomam decisões no sentido de tentar criar seus próprios ambientes e mercados através de compromissos com parceiros de negócios selecionados que são engajados em novos objetivos organizacionais e novos segmentos de mercado, permitindo a um grande número de empreendedores não buscar informação preditiva, tanto quanto possível.

O tema "empreendedorismo" é amplo e impreciso em sua definição. Demanda, portanto, uma visão multiparadigmática do fenômeno, de modo que novas idéias e reflexões permitam aos pesquisadores compor um quadro mais preciso da atividade empreendedora.

Este ensaio perpassou diversos temas e proposições que podem ser pontos de partida interessantes para a ampliação do entendimento do fenômeno do empreendedorismo e da abordagem Effectuation.

Como sugestão para estudos futuros, algumas possibilidades são apresentadas: 
- Empreendedores de diferentes contextos (regiões) utilizaram (ou utilizam) processos decisórios alinhados à estratégia Effectuation ao longo da criação de suas empresas?

- Empreendedores que seguem a estratégia Effectuation estariam mais preparados para gerenciar os fracassos e com isso criar empresas mais bem sucedidas no longo prazo?

\section{REFERENCIAS}

Ansoff, H. I.; Mcdonnell, E. J. Implantando a Administração Estratégica. São Paulo: Atlas, 1993.

Carland, J. W.; Hoy, F.; Boulton, W. R. Differentiating entrepreneurs from small business owners: a conceptualization. Academy of Management Review, Briarcliff Manor, v. 9, n. 2, p. 354-349, Apr. 1984.

Castanhar, J. C. Empreendedorismo e Desenvolvimento Regional no Brasil: Uma Análise da Relação Entre a Criação de Empresas e o Desenvolvimento Regional ao Longo do Tempo e de Estratégias de Empreendedores Selecionados. Tese de Doutorado. Instituto Superior de Ciências do Trabalho e da Empresa: Lisboa, 2007.

Dollinger, M. J. Entrepreneurship: Strategies and Resources. BURR RIDGE: AUSTON PRESS, IRWIN, 1995.

Dornelas, J. C. A. Empreendedorismo: transformando ideias em negócios. Rio de Janeiro: Campus, 2001.

Drucker, Peter Ferdinand. Inovação e espírito empreendedor: (entrepreneurship): prática e princípios. São Paulo: Pioneira, 1986.

Filion, Louis Jacques. Empreendedorismo: empreendedores e proprietários-gerentes de pequenos negócios. Revista de Administração da USP, São Paulo, v. 34, n. 2, abr./jun. 1999.

Gartner, W. B. A Conceptual Framework for Describing The Phenomenon of New Venture Creation. Academy of Management Review v.10, n.4, p. 696-706, 1985. 
GEM [Global Entrepreneurship Monitor]. Empreendedorismo no Brasil: 2009. Curitiba: Instituto Brasileiro da Qualidade e Produtividade, 2010.

Hisrich, R.D; Peters, M.P. Entrepreneurship. New York: McGraw Hill, 2002.

Julien, Pierre-André. Empreendedorismo regional e a economia do conhecimento. São Paulo: Saraiva: 2010.

Mintzberg, H.; Waters, J.A. Tracking strategy in an entrepreneurial firm. Academy of Management Journal. V.25, n.3, p.466-499, 1982.

Mintzberg, H. Patterns in strategy formation (in strategy formulation). Management Science, v.24, n.9, p. 934-948, 1978.

Oliveira Filho, João Bento de; Grossi, Roseane. Os Fatores Ambientais, o Processo Empreendedor e a Formulação Estratégica em Pequenas e Médias Empresas. In: Anais do VI EGEPE, Recife/PE 14 a 16 de Abril de 2010.

Paiva Jr, F. G.; Cordeiro, A. T. Empreendedorismo e o espírito empreendedor: uma análise da evolução dos estudos na produção acadêmica brasileira. In Anais do XXVI Encontro Nacional da Associação dos Cursos de Pós-graduação em Administração, 2006.

Peixoto, Daniel Lanna.; Nery, Manoel Fernandes. Sobre o Processo de Formulação de Estratégias: visões múltiplas, contra-hegemônicas e possíveis para a pequena empresa. In: Anais do VI EGEPE, Recife/PE 14 a 16 de Abril de 2010.

Pelogio, Emanuelly Alves.; Rocha, Luiz Célio Souza.; Machado, Hilka Vier.; Añez, Miguel Eduardo Moreno. Criação de Empresas à Luz do Modelo de Decisão Effectuation: Um Estudo com Mulheres Empreendedoras no Município de Currais Novos/RN. In: Encontro da Associação Nacional de Pós-Graduação e Pesquisa em Administração. Anais Eletrônicos. Rio de Janeiro, 2011.

Porter, M.E. Competitive Strategy: Techniques for analyzing industries and competitors. New York: Free Press. 1980.

Sarasvathy, S. D. Effectuation: Elements of Entrepreneurial Expertise. Cheltenham: Edward Elgar Publishing Limited, 2008.

Sarasvathy, S. D.; Dew, N.; Read, J. S.; Wiltbank, R. What effectuation is not: further development of an alternative to rational choice. Working paper. International Institute for Management Development, Lausanne, 2005. 
Sarasvathy, S. D. Entrepreneurship as a Science of the Artificial. Journal of Economic Psychology, 24(2): 203-220, 2002.

Sarasvathy, S. Causation and Effectuation: Towards a theoretical shift from economic inevitability to entrepreneurial contingency. Academy of Management Review. V. 26, p. 243-288. 2001a.

Sarasvathy, S. Effectual reasoning in entrepreneurial decision making: Existence and bounds. Best paper proceedings, Academy of Management. Washington, p. 3-8, $2001 \mathrm{~b}$.

Schumpeter, Josepf Alois. Teoria do desenvolvimento econômico: uma investigação sobre lucros, capital, crédito, juro e o ciclo econômico. São Paulo: Nova Cultural, 1988.

Tasic, I. A. B. Estratégia e Empreendedorismo: decisão e criação sob incerteza. Dissertação de Mestrado. FGV: São Paulo, 2007.

Whittington, Richard. O que é estratégia. São Paulo: Thomson, 2002.

Wiltbank, R.; Dew, N.; Read, S.; Sarasvathy, S. What To Do Next? The Case For Non-Predictive Strategy. Strategic Management Journal, v. 27, p. 981-998, 2006.

Recebido: 05/03/2013

Aprovado: 30/04/2013 